\title{
Nurse practitioners, medical negligence and crime: A case study
}

\author{
Hui-Man Huang ${ }^{* 1}$, Fan-Ko Sun ${ }^{2}$, Ya-Fen Lien ${ }^{3}$ \\ ${ }^{1}$ Department of Nursing, Chang Jung Christian University, Taiwan \\ ${ }^{2}$ Department of Nursing, I-Shou University, Taiwan \\ ${ }^{3}$ Department of Nursing, Meiho University, Taiwan
}

Received: March 4, 2015

DOI: $10.5430 /$ cns.v3n4p21
Accepted: June 13, 2015

Online Published: June 27, 2015

\begin{abstract}
Background: Medical negligence litigation has become a worldwide concern, but the topic of nurse practitioner negligence has been neglected in Taiwan.

Purpose: The main purpose of this study is to examine how medical negligence is being committed through a study of the factors contributing to the medical negligence of a specific defendant nurse practitioner (NP).

Methods: A case study design was used to achieve the research objectives. Taiwan Kaohsiung District Court Criminal Judgment Yi-Su-Zi No. 2 (2012) was selected as the study case.

Results: Eight failures in patient care contributed to the medical negligence of the defendant NP, who failed to effectively communicate with on-duty nursing staff, promptly inform the designated physician about the patient deterioration, monitor for patient's deteriorating condition; implement interventions in a timely manner, appropriately evaluate the patient, follow facility procedures, implement routine work responsibly, and administer medications appropriately. The actions of the defendant NP violated the duty of care and this medical negligence caused the patient's death. Under Taiwanese law, this case represents a violation of Criminal Law Article 14 and Nursing Personnel Act Article 26, and the defendant NP was convicted.

Conclusions: The findings can assist NPs in understanding their legal responsibilities and motivate them to proactively reduce the risk of medical negligence, thereby ensuring quality improvement and patient safety.
\end{abstract}

Key Words: Medical negligence, Nurse practitioner, Standard of care, Case study

\section{INTRODUCTION}

Medical negligence litigation has become an issue of worldwide concern. ${ }^{[1]}$ Criminal prosecution of healthcare providers for medical negligence is not unique to Taiwan's jurisprudence. In Taiwan, Wu, et al. compare convictions of physicians for medical negligence in 2005 with those in 1991. Physicians who committed medical negligence in 2005 were three times more likely to be sued in both civil and criminal courts than those who acted similarly in 1991 (12.4\% in 2005 vs. $4.1 \%$ in 1991 , odds ratio $[\mathrm{OR}]=3.31, p<.001){ }^{[2]}$
Similarly, courts in Japan also see their healthcare providers on trial as criminal defendants of their medical behaviour. In the UK, the issue of medical negligence and patient safety is of greater prominence following scandals such as that at NHS Foundation Trust. ${ }^{[3]}$ Approximately $2 \%$ of nurse practitioners (NPs) have been named as primary defendant in a malpractice case in the US. ${ }^{[4]}$ Thus, criminal prosecution for medical negligence of healthcare providers is a rising issue and worth exploring.

All nurses, including NPs are at risk of being accused of

*Correspondence: Hui-Man Huang; Email: x2156@mail.cjcu.edu.tw; Address: Department of Nursing, Chang Jung Christian University, Taiwan. 
medical negligence. In a medico-legal context "actions" and "failures to act" (omissions) can both be crimes. The crime of omission is defined as the failure to act when a person has the ability to act and is aware of his or her legal responsibility to act. ${ }^{[5]}$ However, surveys of criminal judgments in Taiwan have typically disregarded acts of omission and negligence in nursing. ${ }^{[6]}$ A case study could assist nurses in understanding their legal responsibility to avoid negligence in nursing while performing their duties. Accordingly, this article presents a case study approach and analyse a written verdict of Taiwan Kaohsiung District Court Criminal Judgment Yi-Su-Zi No. $2^{[7]}$ to explore the medical negligence phenomenon related to a failure in NP practice in Taiwan.

\section{BACKGROUND}

\subsection{Nurse practitioners in hospitals in Taiwan}

There are about 265,759 health care workers in Taiwan; including 41,965 physicians and 140,915 nurses. ${ }^{[8]}$ In response to the shortage of physicians in hospitals in Taiwan, a training programme for NPs was established, based on that employed in the United States (USA) ${ }^{[9]}$ In Taiwan, prior to 2006, a professional certificate in nursing could be held by two types of nurse: registered nurses (RNs) and licensed practical nurses (LPNs). In 2006, an NP certification examination was implemented. NPs are RNs who have completed the necessary education to engage in primary healthcare decision making. They are recruited by hospitals and are mainly educated through hospital training programmes. In Taiwan, in 2013, the total number of qualified NPs was 4,463. Forty percent of them worked in medical centres, $50 \%$ in regional hospitals, and $10 \%$ in district hospitals. ${ }^{[10,11]}$ Lin reports that most NPs are female $(\mathrm{N}=560,97.9 \%)$ have earned at least a bachelor degree (90\%), are 38 years old on average, and have an average of 15 years of nursing experience. ${ }^{[9]}$

\subsection{The role and function of NPs in hospitals in Taiwan}

The function of NPs in a wide range of healthcare contexts is to provide evidence-based healthcare and bridge the gap between patients and healthcare teams. ${ }^{[10,12,13]}$ The job task of NPs includes executing patient admission, discharge and transfer procedures, removing surgical sutures, central venous pressure lines, removing and inserting nasogastric intubation tubes, treating wounds, scheduling laboratory tests under physician supervision, executing wound and blood culture, implementing cardiopulmonary resuscitation, prescribing medication under physician supervision, and monitoring blood gas levels. ${ }^{[14]}$ In the USA, in 2012, 18 states and the District of Columbia allowed nurse practitioners to diagnose and treat patients and prescribe medications without a physician's involvement, while in Taiwan, in contrast, the NPs required physician involvement to diagnose, treat or prescribe medications. ${ }^{[15]}$

In Taiwan, the role of NPs in hospitals is to provide continual and comprehensive healthcare to patients by working with physicians ${ }^{[14]}$ requiring the creation of new relationships among a wide range of personnel. ${ }^{[16-18]}$ As reflected in the diverse job tasks, the role of NPs in hospitals is expanding, increasing the associated legal exposure. Consequently, NPs are often the targets of medical negligence litigation and must defend their actions when caring for patients.

\subsection{Negligence in the context of criminal law in Taiwan}

Taiwan has adopted the Continental European form of criminal law and the duty of care is the criterion for judging negligence. In a criminal case, in Taiwan, a person convicted of a crime may be imprisoned, fined or both. Criminal law has the added objective of seeking to achieve deterrence and retribution through punishment. The conditions for the scrutiny of criminal activity under Taiwan criminal law are (1) statement of facts, (2) illegality (justifiable cause), and (3) liability (excuse). ${ }^{[19]}$ Criminal Code Article 14 clearly states that "an act is committed negligently if the actor, although not acting intentionally, fails to exercise that degree of care which he should and could have exercised in the circumstances". ${ }^{[20]}$ The relevant offences include Criminal Code Article 276-II and Article 284-II. Article 276-II which state that: a person, who in the performance of his occupation, negligently kills another, shall be punished with imprisonment or detention for not more than five years; in addition to a fine of not more than 96 US dollars (approximately £180). Article 284-II states that: "A person, who in the performance of his occupation, causes bodily harm to another person by neglect, shall be punished with imprisonment for not more than one year, detention or a fine of not more than 32 US dollars (approximately $£ 60$ ); if serious bodily harm results, imprisonment for not more than three years, detention, or a fine of not more than 64 US dollars (approximately $£ 120)$ ". ${ }^{[20]}$

Negligence has become nearly synonymous with medical malpractice because of the frequent use of the term in medical malpractice lawsuits. ${ }^{[21]}$ The Joint Commission on Accreditation of Healthcare Organizations defines negligence as "failure to use such care as a reasonably prudent and careful person would use under similar circumstances". ${ }^{[22]} \mathrm{Neg}$ ligence is determined based on the following four factors: (1) a duty of care existed; (2) the duty of care was breached; (3) reasonably foreseeable damage was caused; and (4) a causal connection can be identified (the damage is the direct result of negligent acts or omissions). ${ }^{[21]}$

In Taiwan, civil negligence is divided into three subcate- 
gories, differing in the degree of inattention shown. These are (1) minor negligence, which is the failure to act in an exemplary fashion under the circumstances; (2) ordinary negligence, that is failure to act with the same care as the defendant would apply to their own affairs under the circumstances; and (3) gross negligence, which is a conscious and voluntary failure to take the sufficient care that an ordinary person would in fulfilling a duty owed. ${ }^{[23]}$ In Taiwan, these subcategories are not applied in a criminal law context, so no distinction is drawn between minor negligence, ordinary negligence, and gross negligence.

In many countries (including the USA), prosecution for clinical negligence is not generally associated with criminal negligence lawsuits even if a patient's death resulted. Conversely, in medical negligence suits in Taiwan, both criminal and civil law apply. Nearly all courts and scholars in Taiwan agree that criminal negligence is the same as civil negligence, so in practice any deviation from the required standard of care is potentially associated with criminal negligence. ${ }^{\text {[23-25] }}$ Criminal liability for medical negligence is, in a global context extraordinarily rare. Taiwan is one of a few countries that routinely punishes doctors and nurses under the criminal law. ${ }^{[26]}$

\subsection{Medical negligence in nursing}

All nursing professionals, regardless of whether they are NPs or RNs, owe their patients a duty of care. ${ }^{[27]}$ The duty of care and the associated legal liability is imposed whenever a patient is admitted to the hospital for care. A charge of negligence against a nurse can arise from almost any action or failure to act that causes damage to patient health. ${ }^{[28,29]}$ The nurse has a duty of care toward the patient, and if his/her violation of duty caused patient injuries or death, a nurse may be held liable, but it must be shown that the particular acts or omissions were the cause of the loss or damage sustained. Under the Taiwan Criminal code, Criminal prosecution of a nurse may then result.

Nurses can also be held responsible for providing compensation under civil law. Croke has identified six categories of medical negligence that have prompted malpractice lawsuits against nurses, covering topics from "adhere to appropriate standards of care" to "document patient conditions in patient records". ${ }^{[28]}$ Austin states seven legal criteria defining safe and lawful nursing practice: (1) administer medications appropriately; (2) monitor for and report deterioration; (3) communicate effectively; (4) delegate routine work responsibly; (5) document patients' conditions accurately and in a timely manner; (6) know and follow facility policies and procedures; and (7) use equipment appropriately. ${ }^{[30]}$

Published by Sciedu Press

\subsection{Using case study to highlight how to avoid medical negligence in nursing}

By adhering to Austin seven principles of nursing care, nurses help protect their patients, meet the standard of nursing care required in daily practice, and avoid legal problems. The current study examines the characteristics of medical negligence committed by a defendant NP. This case involved a NP in a private regional hospital who's omission behaviours breached the required standard of care. The case highlights how simple omissions in assessment can lead negative outcomes. Specifically, the NP was found guilty of medical negligence, in that they failed to properly assess the patient and promptly report their deteriorating condition to the physician which resulted in the patient's death. It is hoped that this report on the factors contributing to the medical negligence in this case will provide NPs with an example of the application of the principles of criminal liability regarding negligence to situations that they may encounter in daily practice.

\section{METHODS}

\subsection{Design}

Stake considers the case as an object of study. ${ }^{[31]}$ Yin offers practical techniques for analysing differences between and within each case, developing causal relationships with which to create theoretical links between other phenomena. ${ }^{[32]}$ Yin also suggests that a single case study can stand alone. ${ }^{[33]}$ Case study is the study of the particularity and complexity of a single case, to arrive at an understanding of the specific events and their wider relevance. ${ }^{[33]}$ Its utility in nursing has been recently demonstrated. The present case study uses written verdicts from criminal court. This single case was selected as representative of medical negligence involving a NP. ${ }^{[33]}$ Here, the objective was to capture the circumstances and conditions of the medical negligence of the defendant NP. The researchers adopted Yin's approach to the conduct of a single case study to explore the factors contributing to the medical negligence of a defendant nurse practitioner. The researchers also desired to triangulate data from the court's judgment as an evidentiary source to explain the legal- and nursing-problem-related characteristics that contributed to the medical negligence.

\subsection{Data collection}

This study used the written verdicts from a law database in Taiwan, from 2010 to January 2015 as a case-study source. The written verdicts have two strengths: (1) They are stable and can be reviewed repeatedly; (2) They are exact because they contain exact names, references, and details of events. ${ }^{[33]}$ Two cases involved NPs and the delivery of nursing services. Within them, Taiwan Kaohsiung District Court Criminal Judgment Yi-Su-Zi No. 2 was selected as a case of 
"failure to act" in the hope that an analysis of this case would give insight into the criminal omission behaviours of an NP and the circumstances surrounding them.

\section{The case}

The patient in this case study was a middle-aged man who was admitted to a regional hospital for a laminectomy. The defendant NP, a senior specialist, was employed by this hospital and scheduled to care for surgical inpatients. After the laminectomy, the attending resident prescribed both dexamethasone (a steroid) and ibuprofen (an anodyne) to the patient. From 5:00 pm to 10:00 pm on September 23, 2007, on-duty nursing staff reported that the patient had passed a tarry stool three times, and the NP documented that the patient's blood pressure (BP) had dropped to $81 / 54 \mathrm{mmHg}$ at 10:00 pm. Subsequently, the NP prescribed $0.9 \%$ Saline IV infusion for the patient.

After the N/S solution was administered, the NP did not check with the patient's resident for confirmation that this treatment was appropriate and sufficient. Following the N/S solution injection, the patient developed signs of clinical improvement, and the, temporary increase in the patient's BP to $113 / 74 \mathrm{mmHg}$ obscured the patients ongoing continued gastrointestinal bleeding (G-I bleeding), which was caused by an acute duodenal ulcer and arteriolar corrosion. The next morning (September 24, 06:20 am), an on-duty nurse observed that the patient had lost consciousness, and informed the on-call physician for emergency diagnosis and treatment. However, the patients continued G-I bleeding, (indicated by the post mortem finding of a large amount of blood and hematoma in the gastrointestinal tract) caused the patient's death due to hypovolemic shock.

\subsection{Data analysis}

In order to produce findings and an overall understanding of the case, the analytical method developed by the researchers was to code the case data to the concepts of interest by category, producing a concept map, and pattern generation. ${ }^{[27,33]}$ The researchers used logical models as an analytic method. ${ }^{[33]}$ The analytic framework is composed of three categories: antecedents, nursing process, and the characteristics of the nurse. In creating the framework, the researchers were influenced by Kalisch, Landstrom, and Hinshaw's delineation of missed nursing care. Austin's ${ }^{[30]}$ "legal principles of engaging in safe and lawful nursing practice" was also adopted to identify the characteristic categories of causality of medical negligence.

\subsection{Rigors}

Formal procedures maintaining a chain of evidence to ensure the overall quality of this study were: first, the words and phrases from written verdicts were adequately cited to provide specific nursing and legal definitions; second, the law data base contains the actual evidence which the researchers analysed; third, the questions and procedures of this study used the specific legal and nursing definitions consistently; finally, a qualified reviewer verified the link inferred between the research questions and the findings was reasonable. ${ }^{[33]}$

\section{Findings}

\subsection{The facts}

Factual analysis of this case identifies four key points. The allegations against the defendant NP included: (1) failure to check the reports of the nursing staff regarding the deteriorating condition of the patient; (2) failure to monitor the patient's severe bleeding; (3) failure to exercise nursing care, which she should and could have exercised in the circumstances; and (4) failure to promptly inform the physician about the patient's low BP level, causing the treatment of the patient to be delayed for over 8 hours. These facts led to a failure to treat the severe G-I bleeding from arteriolar corrosion in an acute duodenal ulcer which caused hypovolemic shock and, consequently, death. Accordingly, a causal relationship existed between the NP's actions or failure to act and the death of the patient.

\subsection{Findings of nursing analysis}

Various factors affected the defendant NP's ability to provide care. Austin's seven legal principles were adopted to categorise data in this study, and identified eight characteristic categories regarding the defendant NP's behaviour, belonging to three major themes: the antecedents, nursing process, and individual actions of the NP. ${ }^{[34]}$

\subsubsection{Antecedents}

The antecedents of the medical negligence were external to the NP and within the care environment that inhibited the practice of nursing. They included various relationship and communication factors that had an impact on the NP's ability to provide care. The antecedents were poor teamwork among the patient unit team members, between the NP and physicians, and between the nursing staff and the NP. ${ }^{[34]}$

\section{Failure to effectively communicate with on-duty nursing staff}

The role of the defendant NP in this regional hospital had not evolved to include a process of collaboration. The defendant NP did not check the reports which the on-duty nursing staff provided regarding the patient's rapidly failing condition. In addition, the NP did not alert the next on-duty nursing staff to the clinical evidence of tarry-stool times and G-I bleeding. The lack of effective communication between the defendant NP and the on-duty nursing staff was a significant factor 
in the unchecked expansion of the hematoma. The above omissions directly influenced the patient's outcome.

Failure to promptly inform the designated physician of the patient deterioration

In the current case, the defendant NP did not recognise the severity of the patient's condition. Because of this, the NP failed to contact the designated physician immediately, or within 1 hour of the BP drop, the maximum interval allowable. Subsequently the NP did not request prompt physician evaluation for any signs of continued bleeding following the surgery. The delay in obtaining physician intervention caused the healthcare team to miss the opportunity to save the patient's life.

\subsubsection{Nursing process}

\section{Failure to monitor for patient's deteriorating condition}

According to the nursing process, the recognized standard of care calls for continually monitoring the patient. After the defendant NP received reports on the tarry stool condition of the patient, she failed to consider the side effects of the medication (dexamethasone and ibuprofen), which can increase the risk of G-I bleeding. This lack of pharmaceutical awareness resulted in the NP's failure to assess patient care needs by, for example, investigating the reason that the patient passed tarry stool three times or closely monitoring for the signs and symptoms of internal G-I bleeding. This failure to recognize changes in patient condition also influenced the patient's outcome.

\section{Failure to implement interventions in a timely manner}

The defendant NP failed to promptly conduct the following appropriate interventions: (1) Medication for preventing ulcers or slowing the bleeding should have been administered instead of only an N/S solution for treating the patient's tarry stool. (2) When the patient's systolic pressure decreased to $81 / 44 \mathrm{mmHg}$ and the patient experienced severe shock, the NP should have considered blood transfusion and the administration of colloidal solution as treatment options.

\section{Failure to appropriately evaluate the patient}

Simultaneously administering a steroid and an anodyne caused the aggravation of the peptic ulcer and internal G-I bleeding. Following the administration of the N/S solution, the defendant NP performed no follow-up actions to evaluate the patient's vital signs and identify the symptoms and signs of hypovolemic shock. The NP also failed to actively seek out the cause of the tarry stools.

\subsubsection{The individual actions of the nurse practitioner}

The medical negligence in patient care was contributed by three actions of the defendant NP: the NP failed to (1) follow facility procedures; (2) implement routine work responsibly; and (3) administer medications appropriately.

\section{Failure to follow facility procedures}

In this case, the defendant NP failed to follow hospital procedure. The defendant NP made medical decisions by prescribing N/S solution to the patient in response to their bleeding. Prescribing medication to the patient without physician's supervision was exceeding her scope of practice and was inconsistent with hospital policy. This behaviour failed to abide by team procedures and was also not acceptable to the hospital.

\section{Failure to implement routine work responsibly}

Prior to administering the N/S solution to the patient, the defendant NP did not discuss the side effect of G-I bleeding associated with the use of dexamethasone and ibuprofen with the patient's resident. In addition, the NP did not proactively arrange for relevant examinations and treatments, such as blood measurement, haemoglobin measurement, and blood transfusion. Thus, the NP failed to implement routine work responsibly.

\section{Failure to administer medications appropriately}

When administering medications, it is necessary to assess the patient's response to treatment. A change in the medical treatment plan may be needed, depending on the patient's response. In this case, the defendant NP used the customary method of administering the N/S solution to compensate for the patient's low BP. Following the injection of the N/S solution, the patient developed signs of clinical improvement temporarily. Improper management of the post-operational medications affected the decisions made about the patient and delayed appropriate patient care.

\subsection{Findings from legal analysis}

The legal analysis of this case involved using two key sources of data for review: the autopsy report and the court judgment.

\subsubsection{The autopsy report}

After reviewing the autopsy report, the forensic doctor determined the direct cause of death: "An acute duodenal ulcer caused severe bleeding, with associated entry of countercurrent blood to the stomach causing a clot and a hematoma to develop. This loss of blood resulted in the patient's death". The autopsy report clearly demonstrated that a clot and a hematoma were associated with patient's death, which the prosecution stressed.

\subsubsection{The court judgment}

The basis for the court's finding of liability was in the four key points of fact, which meant that the duty of care was held to have been breached. The court determined that the defendant NP was guilty of violating Criminal Law Article 14 and 
Nursing Personnel Act Article 26: "when nursing personnel, at the time of practicing nursing, see a patient in an emergency condition, they shall immediately contact a physician and provide substitute first aid in advance". ${ }^{[20,35]}$ The defendant NP received a jail sentence of 6 months, which was suspended for 2 years, and was fined NTD 180,000 (approxi- mately $£ 3,600)$. In addition, in civil litigation, the defendant NP and hospital reached a conciliation agreement of joint liability with the patient's family and paid a final settlement of NTD 4,000,000 (approximately $£ 80,000$ ) to compensate for the patient's death.

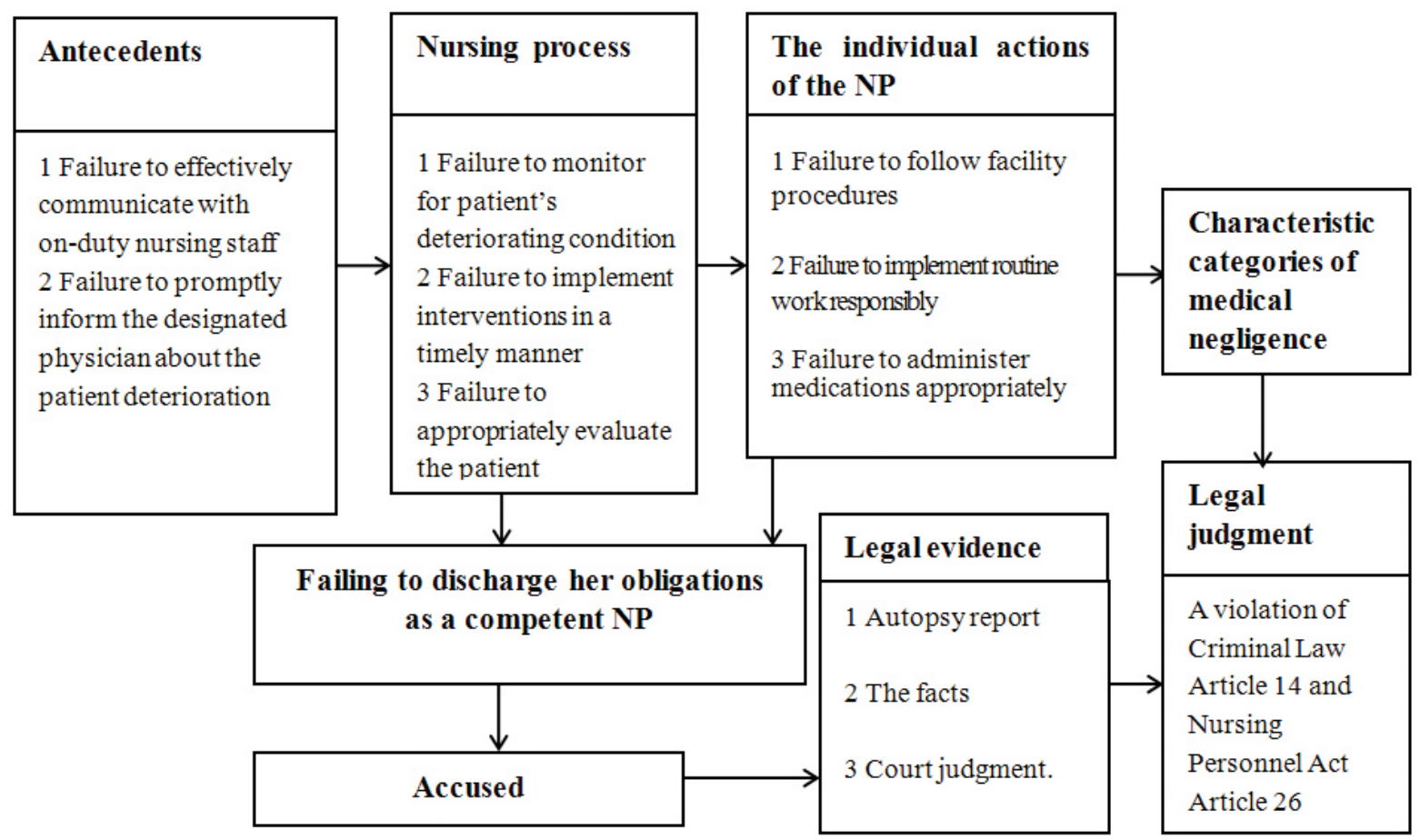

Figure 1. Legal judgment and characteristic categories of medical negligence of the defendant NP

4.4 A model of legal judgment and characteristic categories of medical negligence

The researchers integrate the above analysed results and present the legal judgment as well as characteristic categories of medical negligence in Figure 1.

\section{Discussion}

\subsection{The nursing perspective}

As mentioned previously, Austin states seven legal principles for safe nursing practice. These are seven "must does" in daily practice, and should be applied for all patients to help bring about positive patient outcome and avoid legal liability. By following these principles, both NPs and nursing staff members can proactively reduce the risk of medical negligence in advance to ensure quality improvement. Four guiding questions are proposed to examine medical negligence in the context of this case study.

\subsubsection{Did the NP adjust the priority of the patient?}

An NP should have clinical knowledge that can be used to analyse data and evidence critically and, thus, improve the practice of advanced nursing. ${ }^{[36]}$ The identification of a critical condition requires a precise response. In this case, either the patient's vital signs should have been examined or the symptoms and signs of hypovolemic shock should have been observed directly (for example, systolic pressure $<90 \mathrm{mmHg}$, tachycardia, cold sweating, paleness, and oliguria). The defendant NP should have responded appropriately by adjusting the duty owed to the patient based on the core competency of the NP.

\subsubsection{Was the patient's deterioration foreseeable?}

In this case, the deterioration of the patient's condition might have been foreseeable. The defendant NP knew that the patient had passed tarry stool three times and exhibited low BP, and should have had knowledge of the risks associated with the patient's condition; therefore, she should have provided advanced care for the patient. The aforementioned knowledge should have enabled the deterioration of the patient's condition to be foreseen. However, the NP did not provide effective intervention to reduce the patient's risk of shock. Supervisors and administrators can use this case study as 
an example to provide hospital-based education material for NPs and thus, enhance their core competencies and general awareness of the competencies expected and required of them.

\subsubsection{How was time crucial in this case study?}

The patient experienced internal bleeding for approximately 8 hours. Risk management activities were needed, including identifying the patient's risk of shock, followed by implementing the most advantageous methods of reducing these risks. A good risk management plan could help the NP perform these steps quickly. A reasonable and competent NP would have immediately requested a physician to provide further treatment. In addition, an accurate diagnosis was delayed, allowing the BP of the patient to decrease to levels detrimental to health. This delay indicated inattentiveness to the duty of providing advanced care for the patient. Hwu and Hwu indicated that NPs who provide clinical care services to patients (e.g., assessment, diagnosis, planning, and intervention) should have more extensive knowledge than do nursing staff who are not trained through an NP programme. ${ }^{[1]}$ A reasonable and competent NP would not have allowed 8 hours to pass without implementing adequate intervention to reduce her patient's risk of shock.

\subsubsection{What steps should the NP have taken to prevent in- ternal bleeding after surgery?}

In this case, prior to administering the N/S solution to the patient, the defendant NP should have reviewed the patient's medication to identify those that could have caused internal bleeding. In addition to the failure to act according to the aforementioned standard of care, the NP failed to request immediate consultation with a physician to identify causes of continued bleeding following the administration of the medication. The failure to communicate changes in the patient's condition to the physician was a critical factor in the failure to detect internal bleeding, and caused the delay in obtaining treatment from a physician (which should have been obtained within 1 hour). Furthermore, the NP should have remained with the patient until the bleeding ceased and the physician had assumed the care of the patient.

\subsection{The legal perspective}

The defendant NP was responsible for monitoring the patient and providing appropriate care, and breached her duty of care to the patient. Optimally, the defendant NP would have contacted the on-call physician promptly, discussed the care plan and coordinated the management of the hypovolemic shock (including appropriate blood transfusion) with the physician. A competent and reasonable NP would not have violated the Nursing Personnel Act. The court determined that "this incident could have been avoided". The patient would not have died had he received appropriate healthcare. Finally, based on the causation analysis, it was determined that a causal connection existed between the patient's lack of appropriate care and his death. It was also determined that the incident would not have occurred if the appropriate degree of healthcare had been provided.

In this case, when defence experts agreed that the defendant NP had deviated from the standard of care in several areas, the decision was made to settle the claim on behalf of the NP. The defendant NP violated Criminal Law Article 14 and Nursing Personnel Act Article 26. ${ }^{[20,35]}$ The argument that the pressure associated with daily practice was high was not considered a valid defence, and the statement that "I have fulfilled my professional responsibilities" was considered inaccurate because of the failure to consider the patient's risk of hypovolemic shock, which could have been avoided.

\section{Conclusions}

The case study NP was accused of failing to discharging her obligations as a competent NP. The NP rebutted the charge of criminal negligence. The intervening behaviours of the NP were found to be illegal and culpable. The District Court made a criminal judgment that the NP violated both Criminal Law Article 14 and Nursing Personnel Act Article 26 and was pronounced guilty as charged. ${ }^{[20,35]}$ Eight characteristic categories summarised in this case study contributed the medical negligence of the defendant NP toward patient care. The defendant NP failed to effectively communicate with on-duty nursing staff, promptly inform the designated physician about the patient deterioration, monitor for the patient's deteriorating condition; implement interventions in a timely manner, appropriately evaluate the patient, follow facility procedures, implement routine work responsibly, and administer medications appropriately.

Nurse Practitioners, like other nurses, are at risk of legal liability. ${ }^{[37]}$ An NP can be convicted of manslaughter if their omission exposes the patient to the risk of death and subsequently causes death. Based on this case study, Nps can potentially identify with the issues and learn from mistakes: engaging in nursing practice according to the established standard of care; providing appropriate nursing assessment, intervention and evaluation; and consulting with the on-call physician in a timely manner to identify the cause of unusual clinical findings in patients are required practice. This implies that when NPs have a duty to act in medical environments where risks can occur, they must be capable of foreseeing and averting internal risks to protect patients from harm. 


\section{REFERENCES}

[1] Gündoğmuş UN, O zkara E, Mete S. Nursing and midwife malpractice in Turkey based on the higher health council records. Nursing Ethics. 2004; 11: 489-499. http://dx.doi.org/10.1191/09697 3304ne727oa

[2] Wu CY, Lai HJ, Chen RC. Medical malpractice experience of Taiwan: 2005 versus 1991. International Medical Journal. 2009; 39: 237-242. PMID:19402862. http://dx.doi.org/10.1111/j.1445-5994. 2009.01801.x

[3] Robert Francis QC. The Mid Staffordshire NHS Foundation Trust Public Inquiry Staffordshire NHS Foundation Trust. 2013 [cited 2014 July 13]. Available from: http://www.midstaff spublicinqui ry.com/report

[4] American Association of Nurse Practitioners. NP Fact Sheet. Available from: http://www . aanp.org/all-about-nps/np-f act-sheet

[5] Criminal Code, President Order Hua Chung(1). Yi Tze No. 10200111611 amended. 2013, June 11.

[6] Huang HM, Sun FK. The status of the psychiatric nurse as a guarantor in Taiwan: A case Study. The Journal of Nursing. 2013; 60(6): 57-67.

[7] Taiwan Kaohsiung District Court Criminal Judgment, Yi-Su-Zi No. 2, 2012.

[8] Ministry of Health and Welfare. 2014 Taiwan Health and Welfare Report. The author. 2014.

[9] Lin YL. Manpower of Nurse Practitioner and It's Related Factors in Region and Community Hospital: Qualitative Research. 2012.

[10] The Minister of Health and Welfare. The Evaluation Book for Nurse Practitioners in Training Hospital. 2008.

[11] Tsai SL, Chiu HJ. The current situation and difficulties of practice of nurse practitioners. Journal of Healthcare Quality. 2014; 8: 28-32.

[12] Tuaoia LA, Cashin A, Hutchinson M, et al. Nurse Practitioner preparation: Is it time to move beyond Masters level entry in Australia? Nurse Education Today. 2011; 31: 738-742. PMID:21236523. http://dx.doi.org/10.1016/j.nedt.2010.12.013

[13] National Health Research Institutes Forum. The Training Plan and Practice Regulation in Nurse Practitioners. 2003.

[14] National Health Research Institutes. Nursing workforce and nurse practitioner system: Vision and challenges. 2010.

[15] Health Affairs. Health Policy Brief: Nurse Practitioners and Primary Care. 2012 [cited 2014 July 13]. Author. Available from: http://www.healthaffairs.org/healthpolicybrie fs/brief .php?brief_id=79

[16] Joel LA. Advanced Practice Nursing : Essentials for Role Development. 3rd ed. Philadelphia: FA Davis; 2013.

[17] Hwu LJ, Hwu YJ. Recognition of nurse practitioners by Taiwan's hospital nursing managers. Tzu Chi Nursing Journal. 2010; 9: 71-81.

[18] Chang IW, Shyu YI, Tsay PK, et al. Comparison of nurse practitioners' perceptions of required competencies and self-evaluated competencies in Taiwan. Journal of Clinical Nursing. 2012; 21: 2679-2689.
PMID:22889451. http://dx.doi.org/10.1111/j.1365-2702 . 2012.04186.x

[19] Kao KK. Case analysis in Criminal Law-Application of the theory of crime evaluation. Fu Jen Law Review. 2004; 28: 221-248.

[20] Criminal Code, President Order Hua Chung (1) Yi Tze No. 10200111611, amended in June 6, 2013.

[21] McWay DC. Legal Aspects of Health Information Management. 2nd ed. USA: Thomson learning Inc; 2003.

[22] Byers JF, White SV. Sentinel event glossary of terms/patient safety: Principles and practice. The Joint Commission on Accreditation of Healthcare Organizations. New York: Springer; 2004. 532 p.

[23] Chang MW. A discussion on criminal negligence: Based on criminal cases of medical malpractice in the United States. National Taiwan University Law Journal. 2010; 39: 353-401.

[24] Taiwan Supreme court criminal judgment, No. 3534. 2004.

[25] Taiwan high court criminal judgment, Shang-Su-Zi No. 592. 2003

[26] Lin pj. Criminal judgments to medical malpractice in Taiwan. Legal Medicine. 2009; 11: S376-S378. PMID:19261531. http://dx.doi .org/10.1016/j.legalmed.2009.01.006

[27] Huang HM, Liao CC. A case study on duty of care in professional nursing. The Journal of Nursing. 2013; 60: 76-85.

[28] Croke EM. Nurses, negligence, and malpractice: An analysis based on more than 250 cases against nurses. American Journal of Nursing. 2003; 103: 54-63. PMID:14501474. http://dx.doi.org/10.10 97/00000446-200309000-00017

[29] Joint Commission International. Joint Commission International Accreditation Standards For Hospitals. 4th ed. Joint Commission International, Illinois: OakbrookTerrace; 2012.

[30] Austin S. 7 legal tips for safe nursing practice. Nursing Critical Care. 2010; 5: 15-20.

[31] Stake R. Case studies. In Handbook of Qualitative Research. Denzin N. \& Lincoln Y. eds. Sage: Thousand Oaks CA; 1994.

[32] Yin RK. The abridged version of case study research design and method. In Handbook of Applied Social Research Methods. Bickman L. \& Rogg D. eds. Sage: London; 1998.

[33] Yin RK. Case Study Research: Design and Methods. 5th ed. California: Sage Publications; 2014. 52 p, 106 p, 127 p, 142 p.

[34] Kalisch BJ, Landstrom GL, Hinshaw AS. Missed nursing care: A concept analysis. Journal of Advanced Nursing. 2009; 65: 1509-1517. PMID:19456994. http://dx.doi.org/10.1111/j.1365-2648. $2009.05027 . x$

[35] Nursing Personnel Act. Amended in Dec 21. 2011

[36] National Organization of Nurse Practitioner Faculties. Nurse Practitioner Core Competencies. 2011. Available from: http: //c.ymcdn.com/sites/www.nonpf .org/resource/resmgr/ imported/IntegratedNPCoreCompsFINALApril2011.pdf

[37] Zwijnenbergn NC, Boursg JJW. Nurse practitioners and physician assistants in Dutch hospitals: Their role, extent of substitution and facilitators and barriers experienced in the reallocation of tasks. Journal of Advanced Nursing. 2012; 68: 1235-1246. PMID:21899594. http://dx.doi.org/10.1111/j.1365-2648.2011.05823.x 